\title{
Primary Wrist Hemiarthroplasty for Irreparable Distal Radius Fracture in the Independent Elderly
}

\author{
Guillaume Herzberg, MD, PhD ${ }^{1} \quad$ Marion Burnier, MD $\quad$ Antoine Marc, MD ${ }^{1} \quad$ Yadar Izem, MD ${ }^{1}$ \\ ${ }^{1}$ Wrist Surgery Unit, Herriot Hospital, Lyon, France \\ Address for correspondence G. Herzberg, MD, PhD, Wrist Surgery \\ J Wrist Surg 2015;4:156-163. \\ Unit, Herriot Hospital, Pavillon T., 5 Place d'Arsonval, 69437-LYON \\ Cedex 03, France (e-mail: guillaume.herzberg@chu-lyon.fr).
}

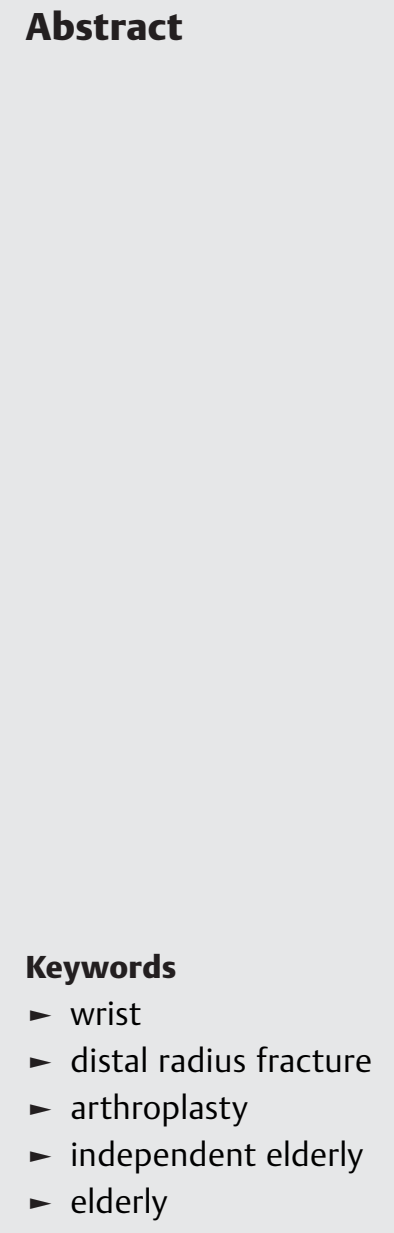

Background Volar plating for acute distal radius fractures (DRF) in the elderly has been recommended. Some studies have suggested that open reduction with internal fixation (ORIF) in this situation results in frequent complications.

Our purposes were to provide a definition of irreparable DRF in independent elderly patients and to review the results of a preliminary retrospective series of wrist hemiarthroplasty (WHA) in this patient population.

Materials Between 2011 and 2014, 11 consecutive independent elderly patients (12 wrists) with irreparable intra-articular DRF were treated with primary WHA at the acute stage. A resection of the ulnar head was associated in nine wrists. A total of 11 wrists with more than 2 years of follow-up form the basis of this paper.

Description of Technique The approach was dorsal longitudinal. An osteotome longitudinally entered the dorsal aspect of the fracture medial to the Lister tubercle. Two thick osteoperiosteal flaps were elevated radially and ulnarly in a fashion similar to opening a book. The distal radius articular surface was excised. The implant was pressed into the radial canal with attention to restoring distal radius length. The two osteoperiosteal flaps were brought back together and sutured so as to close, again like a book, the osseous and soft tissues around the implant.

Results At mean follow-up of 30 months, average visual analog scale (VAS) pain was 1 / 10. Mean QuickDASH (Disabilities of the Arm, Shoulder and Hand) score was 32, and mean Patient-Rated Wrist Evaluation (PRWE) score was 24. Mean forearm rotation arc was $151^{\circ}$. Mean active flexion-extension arc was $60^{\circ}$. Mean active extension was $34^{\circ}$. Mean grip strength was $14 \mathrm{~kg}$ (64\% of contralateral wrist). Mean Lyon wrist score was $73 \%$. Bone healing around the implants was satisfactory in all but one case.

Conclusions Out data suggest that treatment of irreparable DRF in the independent elderly patient with a bone-preserving WHA may be a viable option. Longer-term followup and comparative studies are needed to confirm the validity of this concept.
Open reduction and internal fixation (ORIF) with volar plating for acute distal radius fractures (DRF) is widely used, even for elderly patients. ${ }^{1,2}$ However, some studies have recently questioned its use for DRF in the elderly. ${ }^{3,4}$ It has been suggested that ORIF fails to confer a clinical benefit and results in frequent complications. ${ }^{3,4}$
Roux $^{5,6}$ proposed to treat elderly patients presenting with acute DRF with a wrist hemiarthroplasty (WHA). His preliminary series included six wrists operated on at the acute stage. Vergnenègre, ${ }^{7}$ using the same implant, reported satisfactory clinical and radiological results in eight patients.
Copyright $\odot 2015$ by Thieme Medical Publishers, Inc., 333 Seventh Avenue, New York, NY 10001, USA. Tel: +1(212) 584-4662.
DOI http://dx.doi.org/ 10.1055/s-0035-1558841. ISSN 2163-3916. 


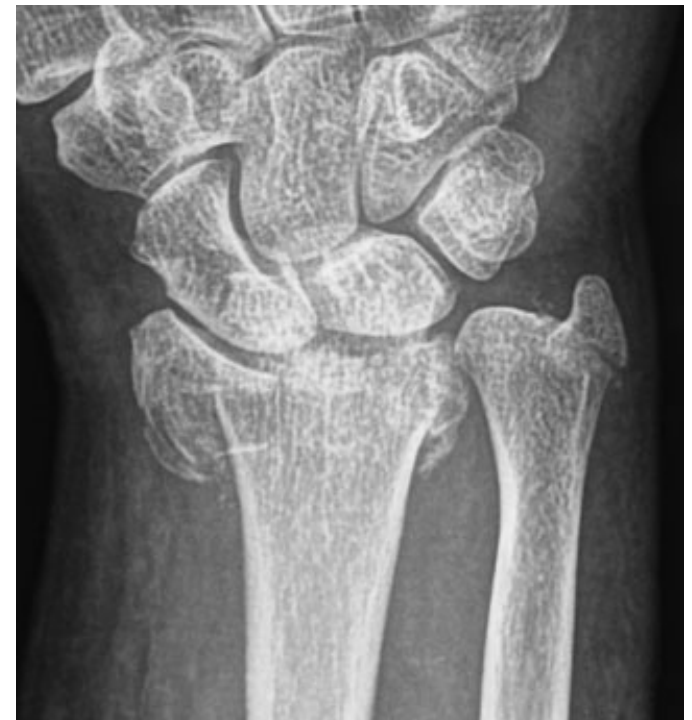

Fig. 1 Posteroanterior (PA) view of an irreparable DRF in a disabled independent 65-year-old woman. See text for radiological criteria.

Our hypothesis was that some complex impacted intraarticular DRF in the elderly would be amenable to treatment with a new bone stock-preserving wrist WHA. This surgery would obviate the need for hardware removal in the absence of complications and would be followed by early mobilization.

The purpose of this paper was (1) to provide a definition of irreparable DRF in the independent elderly patient and (2) to review the results of a preliminary prospective series of WHA for this subgroup of patients.

\section{Patients and Methods}

Between 2011 and 2014, 11 consecutive independent elderly patients (12 wrists) with irreparable intra-articular DRF were treated with primary WHA at the acute stage at a single institution. A resection of the ulnar head was associated in nine wrists (83\%). A total of 11 wrists with more than 2 years of follow-up form the basis of this article.

Inclusion criteria were patients aged more than 65 years, living at home without any help for their activities of daily living, and presenting with a so-called "irreparable DRF," operated on with WHA at the acute stage. The follow-up duration had to be greater than 2 years. Fractures were considered as irreparable if they displayed a combination of six criteria, which are included in the criteria related to the patient/energy of the accident/characteristics of the fracture (PAF) chart: ${ }^{8,9}$ AO type " $\mathrm{C}$ " complete intra-articular fracture, high extra- and intra-articular displacement scores exceeding $6 / 12$, main fracture line distal to the watershed line, impaction, and circumferential comminution (-Fig. 1 and -Fig. 2).

Exclusion criteria were irreparable DRF in dependent patients, failure of a previous treatment for DRF, and follow-up duration of less than 2 years. All patients meeting the inclusion and exclusion criteria constituted the cohort of this study. This retrospective study was approved by our institutional review board (IRB).

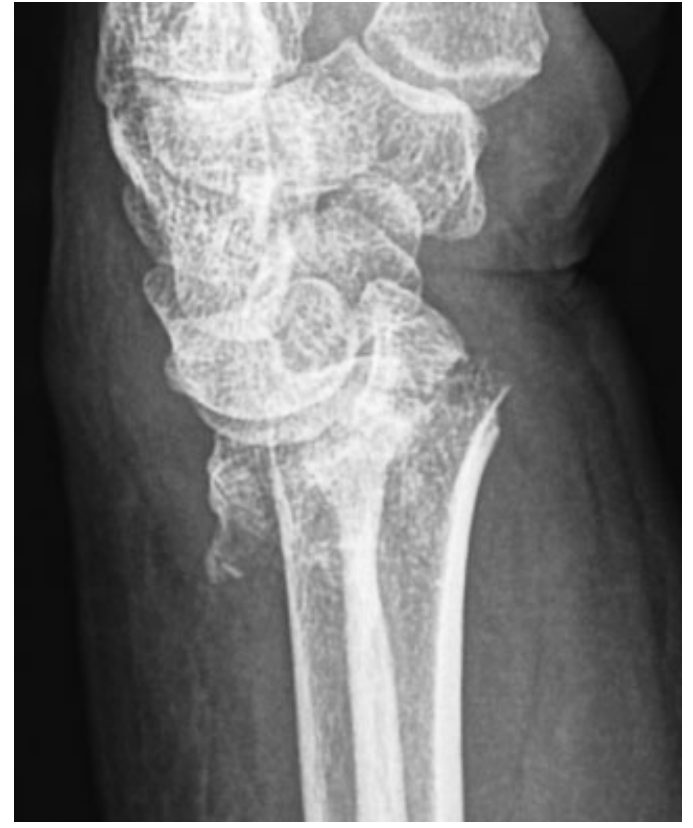

Fig. 2 Same patient, lateral view. In this particular patient, satisfactory ORIF with volar plating would be very difficult to achieve. Treatment with closed reduction-casting or external fixation would be debatable regarding their efficacy.

All patients were female. The average age was 76 years (minimum 65 years, maximum 88 years). All patients had some degree of comorbidities ( - Table 1 ) but were living at home without any help for activities of daily living. All patients underwent primary surgery for acute irreparable DRF. The average time from injury to surgery was 4 days (minimum 1, maximum 7 days). The average follow-up was 30 months (minimum 24 months, maximum 41 months).

\section{Implants}

In 9 wrists we used the radial component of the press-fit ReMotion total wrist arthroplasty (Small Bone Innovations,

Table 1 Comorbidities of the patients analyzed in the current series

\begin{tabular}{|l|l|}
\hline & Comorbidities \\
\hline Patient 1 & $\begin{array}{l}\text { High blood pressure (HBP), } \\
\text { depression disorder }\end{array}$ \\
\hline Patient 2 & Depression disorder, splenic disease \\
\hline Patient 3 & HBP \\
\hline Patient 4 & Systemic acute lupus \\
\hline Patient 5 & HBP, polyneuritis \\
\hline Patient 6 & Hypothyroidism, depression disorder \\
\hline Patient 7 & Renal disease \\
\hline Patient 8 & HBP, colic cancer, cardiac arhythmia \\
\hline Patient 9 & Cardiovascular disease \\
\hline Patient 10 & Bowel disease \\
\hline Patient 11 & HBP, chronic alcoholism \\
\hline
\end{tabular}


Morrisville, PA, USA). ${ }^{10}$ In two wrists we used the press-fit Cobra implant (Groupe Lépine, Lyon, France), a new implant specifically designed for fractures. The Cobra implant has an adequate stem length to facilitate implant placement and primary stability. Two lateral flanges are provided to help rotational control. Two intraflange holes are available to help peripheral bone fixation with sutures if necessary. The Cobra implant includes a volar offset to replicate the shape of the distal radial epiphysis (-Fig. 3). Both Re-Motion and Cobra implants are provided in right and left versions.

\section{Operative Technique and Postoperative Management}

An $8-\mathrm{cm}$ dorsal longitudinal cutaneous incision is made in line with the third metacarpal. The extensor retinaculum is opened at the third compartment level and the extensor pollicis longus (EPL) tendon is retracted.

A sharp osteotome is used to enter longitudinally the comminuted dorsal aspect of fracture just medial to the Lister tubercle up to the radius diaphysis proximally. The periosteum covering the distal part of the radius diaphysis is elevated. By doing so, the posterior interosseous nerve is automatically resected. In line with this fracture rent, a longitudinal $1-\mathrm{cm}$ incision, preserving the dorsal intercarpal ligament and dorsal scapholunate ligamentous complex, is made into the dorsal wrist capsule to expose the convexity of the first carpal row. With the osteotome, two thick osteoperiosteal flaps (5 to $7 \mathrm{~mm}$ thickness) are elevated radially and ulnarly in a fashion similar to opening a book. The radial flap contains the second extensor compartment (which is not opened) and the dorsal and radial part of the distal radius fracture, including the radial styloid. The ulnar flap contains the fourth extensor compartment (which is not opened) and the medial-dorsal part of the distal radius fracture ( - Fig. 4). The comminuted distal radius articular surface and central epiphyseal cancellous bone are excised.

Care is taken to preserve thick peripheral dorsal, lateral, and volar osteoperiosteal flaps to save the bone stock of the

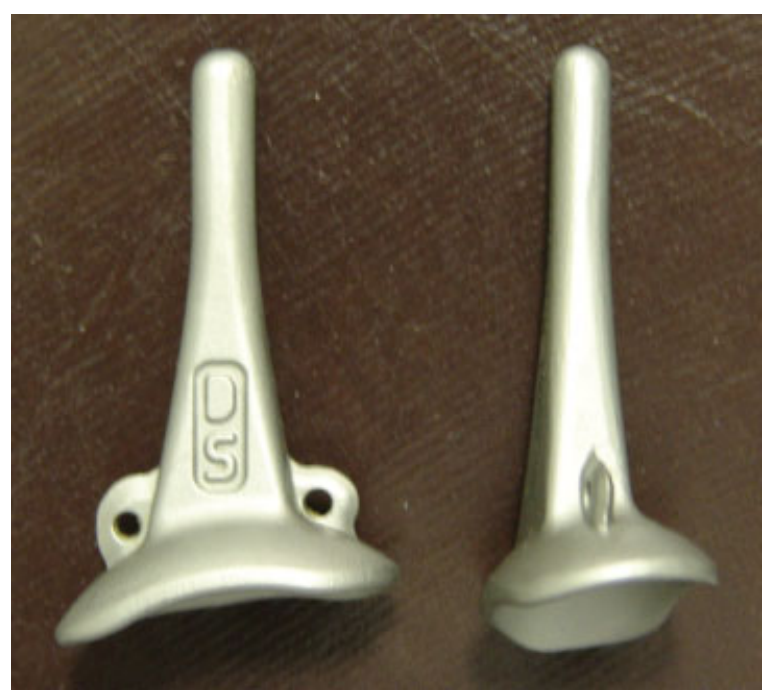

Fig. 3 PA and lateral views of the new Cobra implant. distal radius and facilitate bony surrounding of the implant at the end of the procedure. If the sigmoid notch remnants are reparable, they are approximated with transosseous nonabsorbable sutures and the ulnar head is left intact for later distal radioulnar joint (DRUJ) salvage. If the sigmoid notch remnants are too comminuted to be repaired, or if there is an associated ulnar head or neck fracture, the ulnar head is removed. We use a slightly oblique distal ulna resection and a stabilization using the volar capsule, which is secured to the dorsal part of the ulnar stump with transosseous sutures. After the wrist is placed on towels allowing $90^{\circ}$ of flexion, the radius diaphysis is broached. The depth of broaching should be planned preoperatively so as to maintain the distal radius length (and variance if the ulnar head is left intact). The implant is gently pressed into the radial canal. The length of the stem should provide primary stability into the radial canal and yet protrude enough to allow satisfactory peripheral bony surrounding at the end of the procedure. Proper restoration of distal radius length is critical. Too long an implant will create too much pressure on the concavity of the proximal carpal row, leading to stiffness, pain, and cartilage injury. Too short an implant will be followed by instability of the proximal row with respect to the distal aspect of the implant, with a high risk of dislocation. There should be not more than $2 \mathrm{~mm}$ of pistoning and a good stability both in flexionextension and dorsal-volar translation.

If the reduction is too loose, bone graft or cement should be used to restore radial length better.

The thick peripheral osteoperiosteal distal radial flaps are brought back together so as to close the peripheral osseous and soft tissues around the implant, again like a book (-Fig. 5). If the osteoperiosteal flap(s) are too thin, the surgeon should add part of the cancellous bone that was just removed from the central part of the distal radius epiphysis.

Nonabsorbable transosseous sutures are used to stabilize the bone stock around the implant. By doing this, the

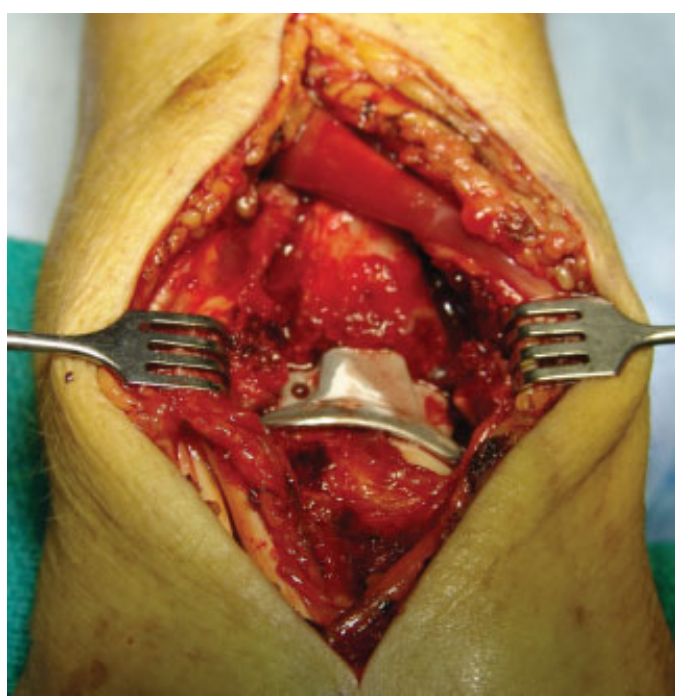

Fig. 4 Through a longitudinal approach, the radial and ulnar flaps are elevated as described in the text. 
peripheral edges of the implant are covered with bone. This prevents impingement of the extensor tendons on the implant.

If the DRUJ is to be reconstructed, the transosseous sutures inserted into the volar medial and dorsal medial parts of the distal radius are first brought together and tied so as to restore the sigmoid notch. Then the peripheral osteoperiosteal distal radial flaps are brought back together around the implant. The short dorsal capsule incision is closed with two nonabsorbable sutures. During the whole procedure, all the extensor compartments but the third were left intact. The dorsal retinaculum is closed. If the closure of the dorsal retinaculum is too tight, the EPL tendon is left out of the dorsal retinaculum.

After wound closure and drainage, the wrist is immobilized in $20^{\circ}$ extension and neutral radioulnar deviation in a long-arm cast for 3 weeks. Then a volar wrist splint in $20^{\circ}$ wrist extension is applied for 3 weeks. During this period, patient's rehabilitation, alone or with the help of a physiotherapist, is performed. Active wrist extension combined

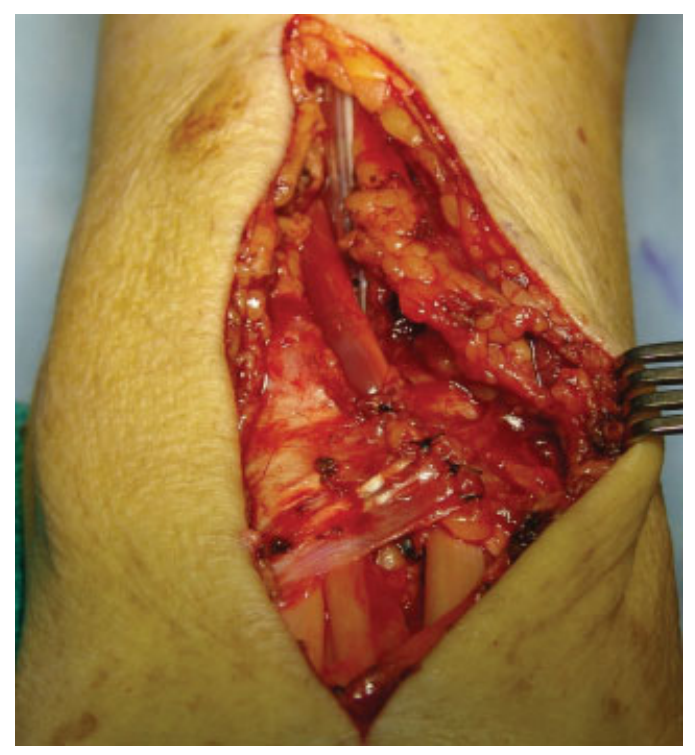

Fig. 5 After implantation of the prosthesis, the two flaps were closed like a book, and the retinaculum was repaired. with long-fingers flexion is encouraged, as well as forearm rotation. Immobilization is discarded at day 45 .

\section{Clinical and Radiological Review}

All patients returned for a comprehensive clinical and radiological review. The follow-up evaluation consisted of an interview, physical examination, and standard anteroposterior (AP) and lateral radiographs.

Follow-up clinical evaluation included rating of pain on a 10-point visual analog scale (VAS), QuickDASH (Disabilities of the Arm, Shoulder and Hand), Patient-Rated Wrist Evaluation (PRWE), evaluation of functional status, range of motion (ROM), and grip strength. The Lyon wrist score ${ }^{11}$ (-Fig. 6), including information about pain, functional limitation with forearm rotation/wrist flexion-extension, active forearm rotation/wrist flexion-extension, and grip strength (Jamar dynamometer) was used. The Lyon wrist score allows a diamond-shaped representation of clinical results, which is not possible with other currently available scores.

Follow-up radiological criteria included search for periprosthetic osteolysis as well as evaluation of ulnar or volar translation of the carpus. Coronal and sagittal inclination of the implant were also evaluated. We measured, in both coronal and sagittal planes, the angle between the longitudinal axis of the radial diaphysis and the stem of each implant. By convention, if the proximal tip of the stem pointed radially/ulnarly in the coronal plane, the implant was considered as ulnarly/radially deviated and the calculated angle was negative/positive. In the sagittal plane, if the proximal tip of the stem pointed dorsally/volarly, the implant was considered as volarly/dorsally deviated and the calculated angle was negative/positive. Only values exceeding $5^{\circ}$ toward either direction were considered as significant. Measurements were done with Centricity Enterprise 3.0 software (GE Healthcare, Little Chalfont, Buckinghamshire, UK).

\section{Results}

\section{Complications}

There were no dislocations, loosenings, or superficial/deep infections of the implants. We did not remove any implants. We observed three instances of complex regional pain

\begin{tabular}{|c|c|c|c|c|c|c|c|c|}
\hline \multicolumn{9}{|c|}{ LYONWRIST'SCORE } \\
\hline Patien & t's Name & & Age & & Side & & Dominance & \\
\hline \multicolumn{9}{|c|}{ Physician's Name } \\
\hline \multirow[t]{2}{*}{ Dato } & & & & & & & & \\
\hline & \multirow{8}{*}{$\begin{array}{l}\text { Pain } \\
\text { Pain } \\
\text { Functional impairement } \\
\text { Functional impairement } \\
\text { Active Motion } \\
\text { Active Motion } \\
\text { Grip Strength }\end{array}$} & \multirow{8}{*}{$\begin{array}{l}\text { with forearm rotation } \\
\text { with Wrist Flexion-extension } \\
\text { with forearm rotation } \\
\text { with wrist flexion-extension } \\
\text { Forearm rotation arc (degrees) } \\
\text { Wrist Flexion - extension arc (degrees) }\end{array}$} & & 0 & 5 & 10 & 15 & 20 \\
\hline$A / 2$ & & & $\bar{A}$ & at sleep & at rest & with motion & heavy use or climatic & none \\
\hline $\mathrm{B} / 2$ & & & B & at sleep & at rest & with motion & heavy use or climatic & none \\
\hline $\mathrm{C} / 2$ & & & $\mathrm{C}$ & severe & important & moderato & minimal & no \\
\hline $\mathrm{D} / 2$ & & & D & severe & important & moderate & minimal & no \\
\hline$E / 2$ & & & $\bar{E}$ & {$[0-40]$} & {$[40-80]$} & {$[80-120]$} & {$[120-160]$} & $>160^{\circ}$ \\
\hline$F / 2$ & & & $\bar{F}$ & {$[0-30 \mid$} & $30-75 \mid$ & $|75-110|$ & {$[110-150[$} & $>150^{\circ}$ \\
\hline G & & & $\mathrm{G}$ & {$[0-25 \%]$} & {$[25-50 \%$} & {$[50-75 \%[$} & {$[75-100 \%[$} & $100 \%$ \\
\hline $\bar{X}$ & Score/80 & Grip strength $(\mathrm{kg})$ : GS1 & & (GS1/GS2 & ) $\times 100:$ (-) & & & \\
\hline $\mathrm{Y}$ & Score/100 & Contralateral Grip strength $(\mathrm{kg})$ : GS2 & & & & & & \\
\hline
\end{tabular}

Fig. 6 Electronic version of the Lyon Wrist Score. 


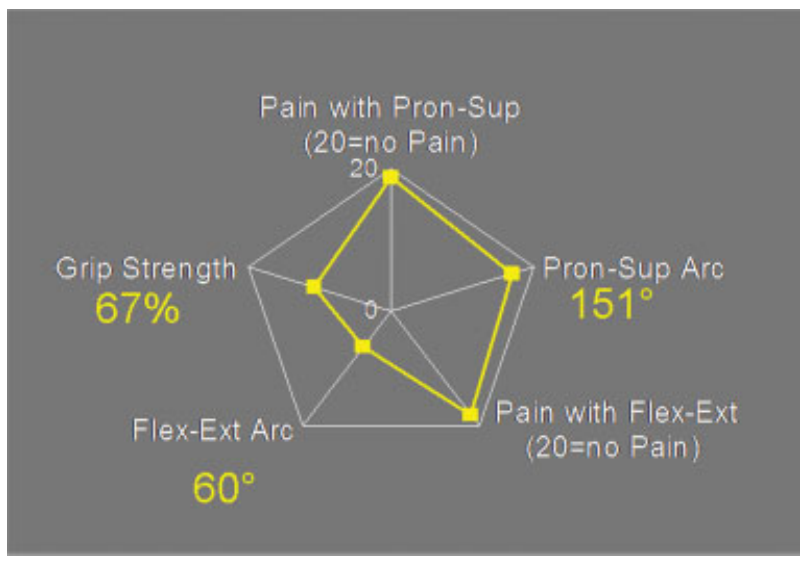

Fig. 7 Diamond-shaped representation of the average values found in this series.

syndrome (CRPS); all resolved in less than 18 months. One patient was reoperated 20 months after the index operation because she presented a significant stiffness due to tendon adhesions along with a tendency to ulnar deviation of the wrist. Through a dorsal approach we performed extensor tendon tenolysis combined with tendon transfer of extensor carpi radialis longus (ECRL) to extensor carpi radialis brevis (ECRB). At final follow-up of 31 months her clinical status was markedely improved and she could make a fist easily.

\section{Clinical Results}

At final follow-up, the average VAS pain was $1 / 10$ (range $0-4$ ). The mean QuickDASH score was 32 (range 0-77), and the mean PRWE score was 24 (range 0-63). Among the nine cases with combined ulnar head resection no patient complained about painful radioulnar impingement. The mean forearm rotation arc was $151^{\circ}$ (range $120-170^{\circ}$ ). The mean active wrist flexion-extension arc was $60^{\circ}$ (range $35-85^{\circ}$ ). The mean active wrist extension was $34^{\circ}$ (range $15-50^{\circ}$ ). The mean grip strength was $14 \mathrm{~kg}$, which was $64 \%$ of the contralateral wrist (range 36-100\%). The mean Lyon wrist score was 73\% (range 62.5-87.5) (-Fig. 7). A case example is shown in - Fig. 8 and - Fig. 9a-f.

\section{Radiological Results}

Bone healing around the implants was satisfactory in all wrists ( - Figs. 10a,b). According to the definitions given in the Methods section, coronal radial inclination of the implant
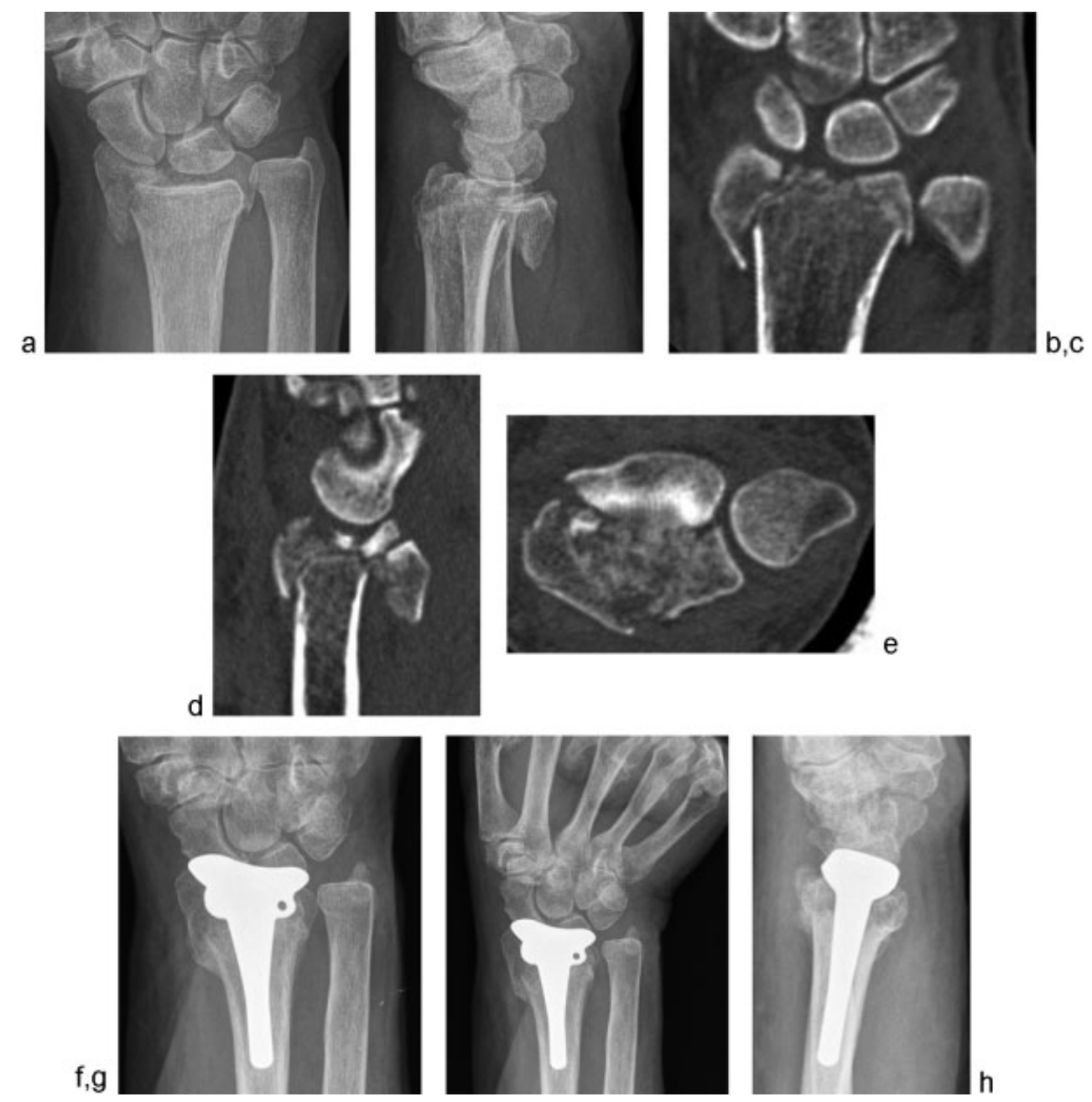

Fig. 8 (a-h) Case example of a 70-year-old woman, independent at home, presenting with irreparable DRF and treated with WHA. Follow-up of this case was 2 years. 
a
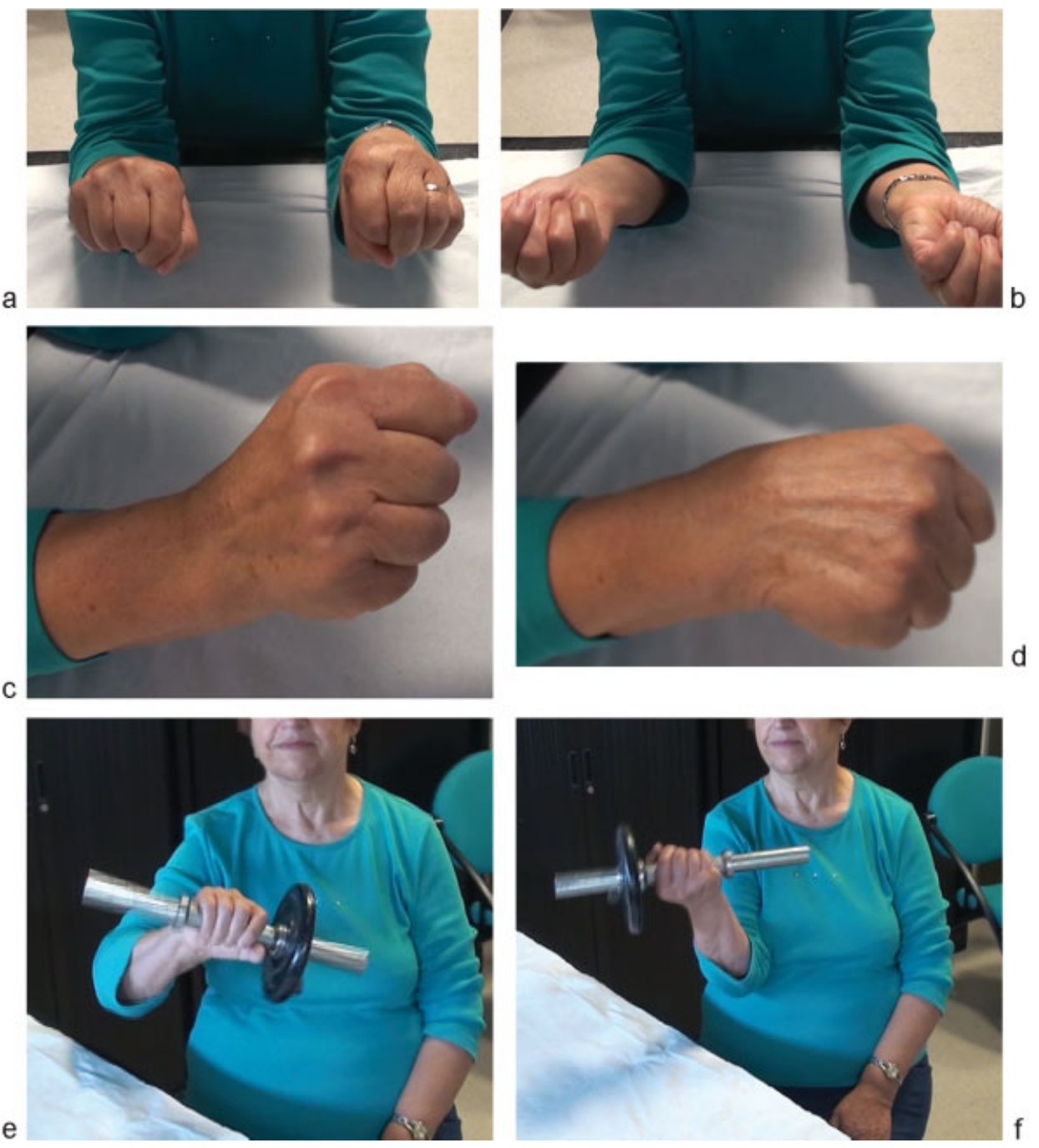

Fig. 9 (a-f) Same patient, clinical result.
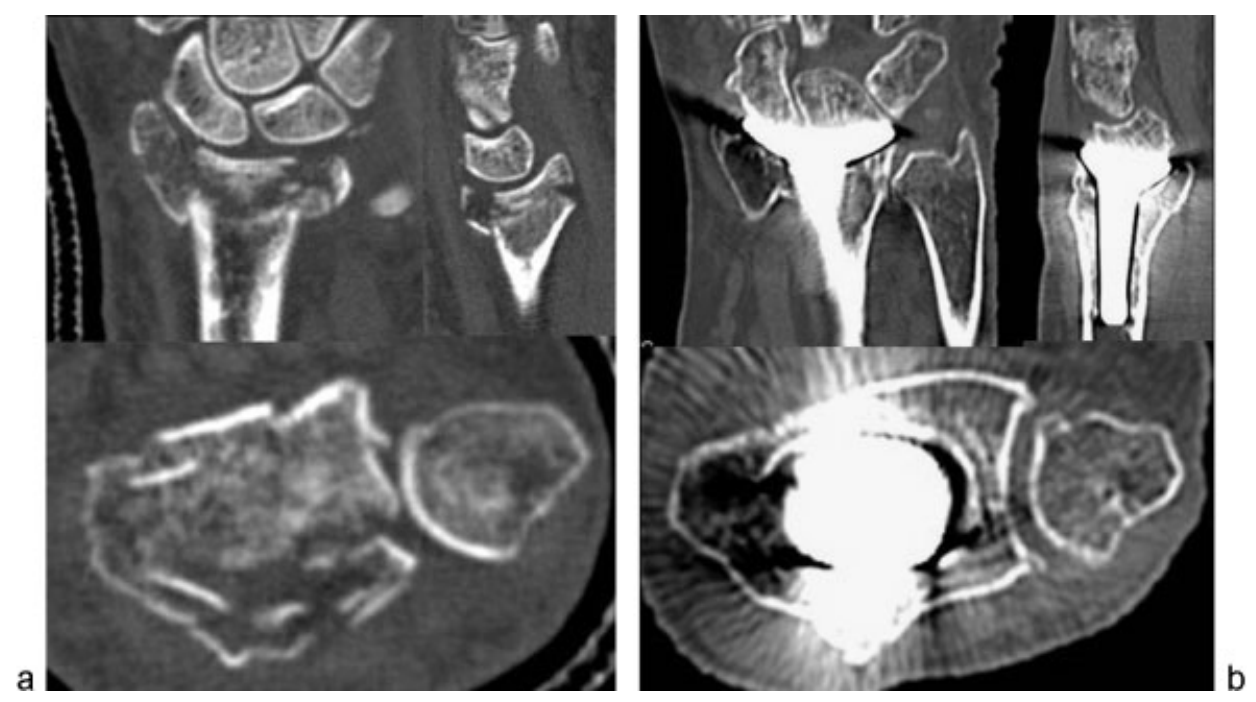

Fig. 10 Case example of satisfactory bone healing around the implant. (a) Preoperative CT scan of an irreparable DRF in an independent elderly woman. Note the marked comminution with impaction and dorsal subluxation of the DRUJ. (b) Postoperative CT scan at 31 months of follow-up showing satisfactory bone healing around the implant and restoration of a sigmoid notch and stable DRUJ. 
Table 2 Patient outcomes compared with literature

\begin{tabular}{|l|l|l|l|l|l|l|l|l|l|}
\hline & $\begin{array}{l}\text { Average } \\
\text { Follow-up } \\
\text { (months) }\end{array}$ & $\begin{array}{l}\text { Pain } \\
\text { (VAS) }\end{array}$ & $\begin{array}{l}\text { Quick } \\
\text { DASH } \\
\text { score }\end{array}$ & $\begin{array}{l}\text { PRWE } \\
\text { score }\end{array}$ & $\begin{array}{l}\text { Lyon } \\
\text { wrist } \\
\text { score }\end{array}$ & $\begin{array}{l}\text { Forearm } \\
\text { rotation } \\
\text { Arc ( }{ }^{\circ} \text { ) }\end{array}$ & $\begin{array}{l}\text { Wrist } \\
\text { flexion/ } \\
\text { extension } \\
\text { arc ( }{ }^{\circ} \text { ) }\end{array}$ & $\begin{array}{l}\text { Wrist } \\
\text { extension } \\
\left({ }^{\circ}\right)\end{array}$ & $\begin{array}{l}\text { Grip strengh } \\
\text { (\% of } \\
\text { contralateral) }\end{array}$ \\
\hline $\begin{array}{l}\text { Vergnenègre } \\
(2014)\end{array}$ & 25 & 2 & 18.2 & NA & 78.6 & 160 & 89 & 44 & 92 \\
\hline $\begin{array}{l}\text { Our series } \\
(2015)\end{array}$ & 27 & 1 & 32 & 25 & 73.1 & 151 & 60 & 34 & 67 \\
\hline
\end{tabular}

was observed in one case and coronal ulnar inclination in three cases (in all of whom the Re-Motion implant was used). This resulted clinically in a slight wrist deformity. This was well tolerated in all four patients. Sagittal orientation of the implant was satisfactory in all cases.

We did not observe any abnormal ulnar or volar translation of the carpus relative to the implant. Each implant remained well seated within the distal cup of the implant. Active motion between the carpus and the implant was proportional to clinical radial/ulnar deviation. There was no subsidence of the implants or erosion of the carpus, but the follow-up is too short to allow definitive conclusions.

\section{Discussion}

Out current data suggest that treatment of irreparable DRF in the independent elderly patient with a bone-preserving WHA may be a viable option. There are no really good options to treat what we have defined as irreparable DRF in elderly patients. Closed reduction and casting may leave significant deformity although functional impairement may be minimal. ${ }^{12}$ Percutaneous pinning often fails because of the very limited purchase into osteoporotic fractured fragments. ${ }^{13}$ External fixation is a cumbersome treatment for an elderly patient. ${ }^{14}$ Distraction plating is an invasive treatment that is more suitable for young patients with irreparable DRF. ${ }^{15}$ Volar plating may be in some cases a satisfactory option. ${ }^{2}$ However, in Orbay's study, ${ }^{2}$ only $33 \%$ were classified as AO type $C$ fractures. In our experience, successful volar plating is difficult to achieve in so-called irreparable DRF in elderly patients, and secondary displacement frequently occurs. Arora $^{3}$ showed in a level I study that ORIF with volar plating in this group of patients did not convey any improvement in terms of function and ROM compared with closed reduction and cast immobilization.

Following concepts used in the shoulder ${ }^{16}$ and elbow, ${ }^{17}$ Roux proposed to treat complex comminuted DRF in the elderly with a specific WHA replacing not only the distal carpal facet of the radius but also the sigmoid notch., Within Roux's series there were six cases of acute DRF in the elderly that were treated with primary WHA. The results of this subgroup were not specifically addressed. Using the same implant, Vergnenègre ${ }^{7}$ reported eight similar cases with satisfactory functional results and no implant removal at an average follow-up of 25 months. Their results were slightly better than ours, especially in terms of grip strength (-Table 2). However, there are some drawbacks about the massive implant used in these studies. According to the recommended surgical technique, the periosteum surrounding the distal radius was in direct contact with the large metallic part of the implant. Moreover, in case of implant removal, the loss of a large solid volume would be very difficult to handle. The use of this implant is contraindicated if the DRF is associated with an ulnar neck or head fracture. This is not the case with the WHA we used in this series.

The implants used in our series have the advantage of preserving the distal radius bone stock. We found that the radial component of the Re-Motion implant was too short to provide a constantly straight orientation of the stem with respect to the radial diaphysis. This is why we designed a specific fracture implant with a similar ellipsoid distal surface but a longer stem and two lateral flanges to help rotational stability.

Because ORIF with volar plate is a validated option in many elderly patients with DRF, we must define the candidates for WHA, both in terms of patients and fractures. This is why we provided simple and reproducible criteria defining irreparable DRF.

Direct metal-on-cartilage contact between the implant and the convexity of the articular cartilage of the proximal carpal row is not the best contact for an arthroplasty. However, WHA for acute DRF in independent elderly patients is a salvage procedure. The metal-on-cartilage contact is well accepted for shoulder and elbow salvage procedures from acute trauma, since the advantages outweight the drawbacks. Moreover, wrist WHA was recently proposed for treatment of wrist arthritis. ${ }^{18,19}$ Longer-term follow-up and comparative studies are needed to confirm the usefulness of the WHA approach for irreparable DRF in independent elderly patients as well as the fate of the cartilage of the first carpal row against the implant.

\section{Conflict of Interest}

There is a conflict of interest with one of the implants presented in this study (Lyon University, Herriot Hospital and corresponding author).

\section{Ethical Statement}

This prospective nonrandomized study was approved by our institutional review board. 


\section{References}

1 Orbay JL, Fernandez DL. Volar fixation for dorsally displaced fractures of the distal radius: a preliminary report. J Hand Surg Am 2002;27(2):205-215

2 Orbay JL, Fernandez DL. Volar fixed-angle plate fixation for unstable distal radius fractures in the elderly patient. J Hand Surg Am 2004;29(1):96-102

3 Arora R, Lutz M, Deml C, Krappinger D, Haug L, Gabl M. A prospective randomized trial comparing nonoperative treatment with volar locking plate fixation for displaced and unstable distal radial fractures in patients sixty-five years of age and older. J Bone Joint Surg Am 2011;93(23):2146-2153

4 Day CS, Daly MC. Management of geriatric distal radius fractures. J Hand Surg Am 2012;37(12):2619-2622

5 Roux JL. Replacement and resurfacing prosthesis of the distal radius: a new therapeutic concept [in French]. Chir Main 2009; 28(1):10-17

6 Roux JL. Treatment of intra-articular fractures of the distal radius by wrist prosthesis. Orthop Traumatol Surg Res 2011;97S:S46-S53

7 Vergnenègre G, Mabit C, Charissoux JL, Arnaud JP, Marcheix PS. Treatment of comminuted distal radius fractures by resurfacing prosthesis in elderly patients [in French]. Chir Main 2014;33(2): 112-117

8 Herzberg G, Izem Y, Al Saati M, Plotard F. "PAF” analysis of acute distal radius fractures in adults. Preliminary results. Chir Main 2010;29(4):231-235

9 Herzberg G. Acute distal radius fractures: PAF analysis. J Wrist Surg 2013;2(2):A-1-A-2

10 Boeckstyns MEH, Herzberg G, Merser S. Favorable results after total wrist arthroplasty: 65 wrists in 60 patients followed for 5-9 years. Acta Orthop 2013;84(4):415-419
11 Herzberg G, Burnier M, Marc A, Merlini L, Izem Y. The role of arthroscopy for treatment of perilunate injuries. J Wrist Surg 2015;4(2):101-109

12 Beumer A, McQueen MM. Fractures of the distal radius in lowdemand elderly patients: closed reduction of no value in 53 of 60 wrists. Acta Orthop Scand 2003;74(1):98-100

13 Glickel SZ, Catalano LW, Raia FJ, Barron OA, Grabow R, Chia B. Longterm outcomes of closed reduction and percutaneous pinning for the treatment of distal radius fractures. J Hand Surg Am 2008; 33(10):1700-1705

14 Capo JT, Rossy W, Henry P, Maurer RJ, Naidu S, Chen L. External fixation of distal radius fractures: effect of distraction and duration. J Hand Surg Am 2009;34(9):1605-1611

15 Richard MJ, Katolik LI, Hanel DP, Wartinbee DA, Ruch DS. Distraction plating for the treatment of highly comminuted distal radius fractures in elderly patients. J Hand Surg Am 2012;37(5):948-956

16 Cadet ER, Ahmad CS. Hemiarthroplasty for three- and four-part proximal humerus fractures. J Am Acad Orthop Surg 2012;20(1): $17-27$

17 McKee MD, Veillette CJ, Hall JA, et al. A multicenter, prospective, randomized, controlled trial of open reduction-internal fixation versus total elbow arthroplasty for displaced intra-articular distal humeral fractures in elderly patients. J Shoulder Elbow Surg 2009; 18(1):3-12

18 Culp RW, Bachoura A, Gelman SE, Jacoby SM. Proximal row carpectomy combined with wrist hemiarthroplasty. J Wrist Surg 2012;1(1):39-46

19 Vance MC, Packer G, Tan D, Crisco JJ, Wolfe SW. Midcarpal hemiarthroplasty for wrist arthritis: rationale and early results. J Wrist Surg 2012;1(1):61-68 